EDUCATION

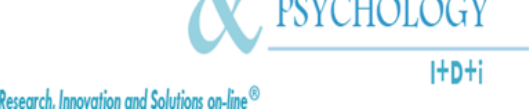

Electronic Journal of Research in Educational Psychology

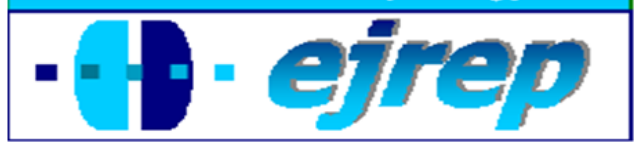

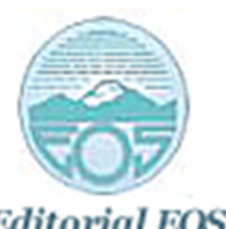

Editorial EOS

\title{
Validation Study of the Scale for Assessment of the Teaching-Learning Process, Student Version (ATLP-S)
}

\author{
Jesús de la Fuente ${ }^{1}$, Paul Sander ${ }^{2}$, Fernando Justicia ${ }^{3}$ \\ M. Carmen Pichardo ${ }^{3}$, Ana B. García-Berbén ${ }^{3}$ \\ ${ }^{1}$ Dept. of Developmental \& Educational Psychology, \\ University of Almería, Spain \\ ${ }^{2}$ University of Wales Institute, Cardiff, UK \\ ${ }^{3}$ Dept. of Developmental \& Educational Psychology, \\ University of Granada, Spain
}

\section{Spain/UK}

Correspondence: Jesús de la Fuentes Arias: Department of Educational and Developmental Psychology.

Faculty of Psychology. University of Almería. Carretera de Sacramento s/n. 04120 La Cañada de San Urbano. Almería, Spain. Tel: + 34950 015354; Fax: +34 950 015083. E-mail: jfuente@,ual.es

(C) Education \& Psychology $\mathrm{I}+\mathrm{D}+\mathrm{i}$ and Editorial EOS (Spain) 


\begin{abstract}
Introduction. The main goal of this study is to evaluate the psychometric and assessment features of the Scale for the Assessment of the Teaching-Learning Process, Student Version (ATLP-S), for both practical and theoretical reasons. From an applied point of view, this selfreport measurement instrument has been designed to encourage student participation in the daily assessment of how the teaching-learning process occurs. From a theoretical point of view, this 30 -item scale was initially developed with rational criteria, inspired by the most common curriculum models; in addition, we propose to empirically validate the instrument.
\end{abstract}

Method. A total sample of 1250 Spanish university students and 275 university students from the UK participated in the assessment. The analyses made to assess its reliability, internal validity (exploratory and confirmatory factorial analysis), and external validity (correlations and MANOVAs).

Results and Discussion. We can be considered adequate and have proved to be powerful enough to define relations with other variables - learning approach, or teaching and learning experiences - in the sample with Spanish and UK versions of the instruments.

Keywords: Teaching-learning process, assessment, higher education, internal and external validity, reliability scale.

Received: 05/18/10 Initial Acceptance: 05/18/10 Definitive Acceptance: 07/29/10 


\title{
Estudio de validación de la Escala para la Evaluación del Proceso de Enseñanza-Aprendizaje, Versión del estudian- tes (EEPEA-E)
}

\begin{abstract}
Resumen
Introducción. El objetivo de este estudio ha sido validar empíricamente el instrumento, a través de la evaluación psicométrica y definir las características de la Escala de Evaluación del Proceso de Enseñanza-Aprendizaje, versión para estudiantes (ATLP-S), tanto por razones prácticas como teóricas. Desde el punto de vista aplicado, este instrumento de medición tipo auto-informe ha sido diseñado para fomentar la participación de los estudiantes en la evaluación diaria de cómo el proceso de enseñanza-aprendizaje tiene lugar. Desde el punto de vista teórico, esta escala de 30 ítems se desarrolló inicialmente con criterios racionales, inspirados en el modelo curricular de los planes de estudio.
\end{abstract}

Método. Una muestra total de 1250 estudiantes universitarios españoles y 275 estudiantes universitarios del Reino Unido participaron en la evaluación. Los análisis realizados para evaluar su fiabilidad, validez interna (exploratorio y confirmatorio análisis factorial), y validez externa (correlaciones y MANOVAS).

Resultados y Discusión. El instrumento puede ser considerado apropiado y ha demostrado ser lo suficientemente potente como para definir las relaciones con otras variables -enfoques de aprendizaje o enseñanza y experiencias de aprendizaje- tanto en la versión española como anglosajona .

Palabras clave: Proceso enseñanza-aprendizaje, evaluación, educación superior, validez interna y externa, fiabilidad.

Recibido: 18/05/10 Aceptación Inicial: 18/05/10 Aceptación Definitiva: 29/07/10 


\section{Introduction}

Since learning is not an isolated and exclusively internal process, it can be guided externally, through the teaching process. This fact has been relevant in defining what should be assessed in educational situations. Thus, as interest in students' learning processes is increasing, interest has also increased in the teaching process which guides the former (Butler \& Shibaz, 2009; De la Fuente \& Eissa, 2010; Cardelle-Elawar, Irving, \& Sanz de Acedo, 2007; Coll, Rochera, Mayordomo \& Naranjo, 2007; Entwistle \& Tait, 1990; Hugener et al., 2009; Husbands \& Fosh, 1993; Kinchin, Lygo-Baker \& Hay, 2008; Ramsden, 2003). This is what has been defined as the construct "teaching-learning process" (hereafter TL), applying to different teaching situations, whether formal or non-formal. In formal teaching situations this process is considered to be the design and development of how its three constituent elements will interact: the curriculum, the teacher's role and the students' role.

Additionally, in recent decades there has been growing interest in teaching-learning processes in Higher Education and in cultural differences (Oyserman, Coon, \& Kemmelmeier, 2002; Postareff \& Lindblom-Yänne, 2008; Trigwell \& Prosser, 2004; Vermunt \& Verloop, 1999). The way most students learn is highly influenced by their native culture; these culturally-defined learning characteristics contrast markedly in students from countries with quite distinct cultures. For example, there is more in common with how British and American students learn than what we find when comparing British students with other Europeans, such as Spaniards or Italians (Klassen, 2004; Tweed \& Lehman, 2002). There is a need to understand how teaching and learning processes modulate one another, depending on the individuals' approach to teaching or learning, respectively (Vermunt \& Verloop, 1999).

\section{Models and Instruments for Assessment of the Teaching-Learning Process}

Several educational models have taken into account this interdependent, systematic teaching-learning process. The Weinstein and Mayer Model (Weinstein \& Mayer, 1986) considers that good teaching must include not only content, but should also teach students how to learn. The Entwisle Model has focused on evaluation of the most important aspects of the TL process in order to improve instructional performance. Other models have accurately defined the variables that should make up assessment of this construct. The Experiences of Teaching 
\& Learning Questionnaire (Entwistle \& McCune, 2004; Hounsell, Entwistle, et al., 20012003 ) is the instrument for evaluation of one Model. It evaluates subjective experiences of the Teaching and Learning Process. Biggs' $3 P$ Model (2001) is focused on the Presage-ProcessProduct factors of the teaching and learning process. The assessment instrument is the RSPQ-2F, the revised Two-Factor Study Process Questionnaire SPQ (Biggs, Kember, \& Leung, 2001) which contains four subscales (Deep Motive; Deep Strategy; Surface Motive and Surface Strategy) aimed at measuring two dimensions: deep and surface learning approaches. Justicia, Pichardo, Cano, Berbén y De la Fuente (2008) showed a confirmatory factorial structure with a Spanish sample, similar to the study by Biggs et al.. (2001), coinciding with a first-order factor structure (two factors).

Finally, the interactive instructional model DEDEPRO, acronym for DesignDevelopment- Product (De la Fuente \& Justicia, 2007; De la Fuente, Justicia, \& Berben, 2006) has made it possible to establish the factors that make up this process, either conceptually or empirically, as well as the instrument for evaluating different Teaching-Learning processes. The scales for Interactive Assessment of the Teaching Learning Process, IATLP, is a long self-report instrument to be completed by both teacher and students (De la Fuente \& Martínez, 2007).

However, one limitation of this more comprehensive assessment instrument is the great number of items included, making it difficult to administer and interpret (Apodaca \& Grad, 2005; Ginns, Prosser, \& Barrie, 2007). For this reason, we assume that there is still a need for simpler instruments that will offer us a quick understanding of the TL process under way, but without overlooking fundamental statistical values nor the complexity of the phenomenon being studied. The scales for Assessment of the Teaching-Learning Process, ATLP, is a short self-report version of the instrument, to be completed by the teacher and the students (De la Fuente \& Justicia, 2001, 2010).

\section{The present study}

The aims of this study are as follows:

1. To verify the reliability and validity values of this version of the ATLP-S, Assessment of the Teaching-Learning Process - Student Version, with Spanish and UK samples.

2. To evaluate the statistical values that support the construct "teaching-learning pro- 
cess", assessed with this new self-report instrument.

3. To establish internal and external validity criteria for this version, through the analysis of interdependent relations between the assessment carried out on the teaching-learning process, on student approaches to learning, and on teaching and learning experiences.

\section{Method}

\section{Participants}

The sample included the following groups: (1) a total of 1250 Spanish students (Universities of Almería and Granada) and 275 UK students (UWIC, Cardiff, UK) for the Research \& Development Project. Sample characteristics are shown in Table 1.

Table 1. Characteristic of the study sample

\begin{tabular}{llllccc}
\hline \multicolumn{1}{c}{ Sample } & Country & University & Degree Prog. & Year & Age & Gender (\%) \\
\hline $1 . \mathrm{N}=1250$ & Spain & UAL, UGR & 7 & $1^{\text {st }}, 4^{\text {th }}$ & $22.11(3.54)$ & $19.5 ; 76.2$ \\
$2 . \mathrm{N}=275$ & UK & UWIC & 1 & $1^{\text {st }}, 2^{\text {nd }}$ & $20.69(4.97)$ & $14.5 ; 51.7$ \\
\hline
\end{tabular}

\section{Instruments}

Assessment of the Teaching-Learning Process, Student version (ATLP-S)

The ATLP is a self-report instrument to be completed by the teacher and the students (De la Fuente \& Justicia, 2001, 2010), in its Spanish and English versions, respectively. It is made up of a quantitative part with 30 items, 15 that evaluate perception of the teaching process and another 15 that evaluate learning process perception. Responses are on a Likert-type scale, with scores ranging from 1 (totally disagree) to 5 (totally agree). It also includes a qualitative part where students can make recommendations for improving each of the processes evaluated.

This instrument has been designed with curriculum criteria, since its aim is to evaluate to what extent the different issues inherent in either the teaching process or the learning process have been addressed. Initially, it was constructed with rational criteria, setting up the items as follows (see Table 2). The Scale's complete composition is presented in the Appendix 1 . 
Table 2. Original and rational item distribution within the Scale (De la Fuente \& Justicia,

2001, 2010)

\begin{tabular}{lll}
\hline Curriculum Aspects & \multicolumn{1}{c}{ Teaching process } & \multicolumn{1}{c}{ Learning Process } \\
\hline Why? & items 1,2 & items 16,17 \\
What for? & items 3,4 & items 18,19 \\
What? & items, 5, 6, 7, 8 & items 20,21, 23, 24 \\
How and when? & items $9,10,11,12,13$ & items 25, 26, 27, 28 \\
Evaluation? & items 14,15 & items 29,30 \\
\hline
\end{tabular}

The R-SPQ-2F, The Revised Two-factor Study Process Questionnaire SPQ (Biggs et al.., 2001).

This instrument contains 20 items in four subscales (Deep Motive; Deep Strategy; Surface Motive and Surface Strategy) aimed to measure two dimensions: Deep and Surface learning approaches. Students are asked to respond to these items on a 5-point Likert-type scale ranging from 1 ('rarely true of me') to 5 ('always true of me'). The R-SPQ-2F was translated into Spanish, adapted to take cultural differences into account, then independently translated back and further modified where necessary. Justicia et al. (2008) showed a confirmatory factorial structure with a Spanish sample, similar to the study by Biggs et al. (2001), with a first order factor structure (two factors).

\section{The Experiences of Teaching \& Learning Questionnaire}

This measurement instrument was used in its Spanish version and in its English version (Entwistle \& McCune, 2004). The original scale was used in the ETL Project, UK (Hounsell, Entwistle et al., 2001-2003) and provides a valid, reliable means to evaluate experiences of the Teaching and Learning Process. For more information, see www.ed.ac.uk/etl/project.html. The values in our samples are: (1) For the 2004/2005 Spanish sample, internal consistency is .93 (Cronbach's alpha), and the Guttman split-half coefficient values are .89 and .88 for the first and second middle Scales, respectively; (2) For the UK 2004/2005 sample, internal consistency is .94 (Cronbach's alpha), and .87 and .91 are the Guttman split-half coefficient values for the first and second middle Scales, respectively. 


\section{Procedure}

These Scales were completed voluntarily and anonymously during class time by university students belonging to different groups, at the end of a four-month period in the same academic year. Part of the data were obtained at different moments of the academic year (February, for scales 2 and 3), and the other part at the end of the year (May-June for scale 1).

\section{Statistical analysis}

First, internal consistency was calculated using the standard means of Cronbach's Alpha and Guttman \& Spearman-Brown split-half reliability coefficients. Second, either the internal or external instrument validity was studied. For internal validity, we used standard exploratory factor analysis with its pre-requisites of both Barlett's Sphericity Test and the Kaiser-Meyer-Olkin measure of sampling adequacy (KMO). The standard factorial or exploratory analysis was carried out by means of the Principal Components extraction method, using the classic statistical package SPSS. Moreover, to obtain a clear factorial solution, Orthotrans/Varimax rotations were implemented. Assessment of internal validity was based on confirmatory factor analysis (CFA), which is part of a more general class of approaches called structural equation modeling (SEM). Structural equation modeling is a technique that has been widely used for instrument validation and model testing (Bentler, 1995). AMOS 16.0 computer software (Arbuckle, 2008) was used to test model fitting. In order to evaluate model fit, several fit indices were computed: the CMIN/DF index or chi-square to its degrees of freedom ratio $\left(\mathrm{X}^{2} / \mathrm{df}\right)$, the comparative fit index (CFI), and the root mean-square error of approximation (RMSEA). These were calculated using the maximum likelihood estimation method, a robust technique that has proven powerful against possible biases caused by violations of the multivariate normality and other statistical assumptions (Bentler, 1995; Bentler \& Dijkstra, 2000).

External validity study was estimated using two different strategies. The first was correlation of the instrument score. In the second, we analyzed interdependent relations between the instrument score for the level of perception of the Teaching and Learning Process, TLP, with (1) Learning Approach, and (2) Teaching and Learning Experiences. For this objective, we defined three levels (low-medium-high) in the perception of TLP, using cluster analysis. ANOVAs and MANOVAs were executed previously using the SPSS 16.0 statistical package. 


\section{Results}

\section{Reliability}

In the Spanish sample we obtained: Cronbach Alpha $=.930$ (complete scale), .930 (first half) and .904 (second half). Spearman-Brown: .8439 and Guttman: .803. For the first sub-scale, Teaching Process: .96 (total), .93 (first half) and .92 (second half). In the second subscale, Learning Process: .94 (total), .93 (first half) and .88 (second half). For the British sample: Cronbach Alpha = .913 (complete scale), .984 (first half) and .847 (second half). Spearman-Brown: .736 and Guttman: .732. For the first sub-scale, Teaching Process: .88 (total), .83 (first half) and .80 (second half). In the second subscale, Learning Process: .85 (total), .80 (first half) and .73 (second half). Thus, reliability rates of the ATLP-S can be considered acceptable.

\section{Internal Validity Criteria}

In the Spanish sample, results from exploratory factor analysis of principal components show that the questionnaire has a two-factor structure (forced). The Bartlett test, a prerequisite to factor analysis, shows a chi-square value $(435)=34456.046 ; \mathrm{p}=.0000$ ), demonstrating that our data structure is valid for the factor analysis. The KMO rate $=.971$ also demonstrates data suitability for factor analysis. The study of this double dimension of the teaching-learning process, was by Principal Components with varimax rotation (rotation with no factor limit and ignoring saturations less than .40). The analysis suggested two factors that explained $51.04 \%$ of the variance. Results from the exploratory factor analysis of main components offer information regarding the two instrument sub-scales.

In the UK sample, results from exploratory factorial analysis of main components show that the questionnaire has a two-factor structure (forced). The Bartlett test, a prerequisite to the factorial analysis, shows a chi-square value $(435)=1482.124(p=.0000)$, demonstrating that our data structure is valid for the factorial analysis. The KMO rate $=.820$ also demonstrates data suitability for factor analysis. The study of this double dimension of the teaching/learning process, was by Principal Components with varimax rotation (rotation with no factor limit and ignoring saturations less than .30). The analysis produced two factors that explained $39.815 \%$ of the variance. Results from the exploratory factor analysis of main 
components offer information regarding the two instrument sub-scales. These results are shown in Tables 3 and 4.

Table 3. First order multiple factor structure obtained in the exploratory factor analysis (Spain).

\begin{tabular}{|c|c|c|c|c|c|c|}
\hline Factor & $\begin{array}{c}\% \text { var. } \\
\text { total }\end{array}$ & $\begin{array}{l}\% \text { var. } \\
\text { partial }\end{array}$ & items & Saturation & Communality & Abbreviated item \\
\hline \multirow{15}{*}{$\begin{array}{c}\text { D1. Teaching } \\
\text { process }\end{array}$} & 31.22 & 31.22 & T15 & .81 & .77 & teaching process appropriate \\
\hline & & & $\mathrm{T} 3$ & .78 & .69 & teaching objectives clear \\
\hline & & & T6 & .77 & .67 & facts/concepts appropriate \\
\hline & & & $\mathrm{T} 8$ & .76 & .67 & attitudinal content appropr. \\
\hline & & & $\mathrm{T} 10$ & .76 & .71 & helps lrng be relevant, useful \\
\hline & & & $\mathrm{T} 4$ & .75 & .68 & tchg objectives helpful \\
\hline & & & $\mathrm{T} 7$ & .75 & .66 & procedural content appropr. \\
\hline & & & T9 & .74 & .67 & tchr encouraged stu. involvmt \\
\hline & & & $\mathrm{T} 2$ & .73 & .64 & tchr explained rationale \\
\hline & & & $\mathrm{T} 13$ & .72 & .57 & teacher behavior appropr. \\
\hline & & & $\mathrm{T} 14$ & .70 & .59 & assessmt strategies appropr. \\
\hline & & & $\mathrm{T} 1$ & .69 & .62 & general approach useful \\
\hline & & & $\mathrm{T} 5$ & .68 & .54 & tchg content appropriate \\
\hline & & & $\mathrm{T} 11$ & .66 & .54 & materials appropriate \\
\hline & & & $\mathrm{T} 12$ & .64 & .51 & time distribution appropriate \\
\hline \multirow{15}{*}{$\begin{array}{c}\text { D2. Learning } \\
\text { process }\end{array}$} & 51.04 & 19.81 & L25 & .80 & .70 & planned \& regulated my lrng \\
\hline & & & L24 & .75 & .65 & actively involved in lrng \\
\hline & & & L30 & .72 & .72 & my lrng process appropriate \\
\hline & & & L27 & .71 & .58 & spent time adequately \\
\hline & & & $\mathrm{L} 21$ & .65 & .64 & facts/concepts covered well \\
\hline & & & L29 & .64 & .46 & self-evaluation of learning \\
\hline & & & $\mathrm{L} 22$ & .62 & .57 & procedures practiced \\
\hline & & & L20 & .61 & .64 & learning content appropriated \\
\hline & & & L26 & .61 & .48 & materials sufficient \\
\hline & & & L23 & .59 & .65 & attitudinal content acquired \\
\hline & & & L16 & .58 & .62 & general structure understood \\
\hline & & & L28 & .58 & .35 & regular attendance \\
\hline & & & L19 & .57 & .67 & my lrng objectives helpful \\
\hline & & & L17 & .53 & .57 & importance of lrng was clear \\
\hline & & & L18 & .50 & .66 & clear learning objectives \\
\hline
\end{tabular}


Table 4. First order multiple factor structure obtained in the exploratory factor analysis $(U K)$.

\begin{tabular}{|c|c|c|c|c|c|c|}
\hline Factor & $\begin{array}{c}\% \text { var. } \\
\text { total }\end{array}$ & $\begin{array}{l}\text { \% var. } \\
\text { partial }\end{array}$ & items & Saturation & Communality & Abbreviated item \\
\hline \multirow{15}{*}{$\begin{array}{c}\text { D1. Teaching } \\
\text { process }\end{array}$} & \multirow[t]{15}{*}{22.965} & \multirow[t]{15}{*}{22.965} & T15 & .79 & .645 & teaching process appropriate \\
\hline & & & $\mathrm{T} 1$ & .73 & .545 & general approach useful \\
\hline & & & $\mathrm{T} 13$ & .69 & .483 & teacher behavior appropr. \\
\hline & & & $\mathrm{T} 7$ & .69 & .476 & procedural content appropr. \\
\hline & & & $\mathrm{T} 10$ & .68 & .490 & helps lrng be relevant, useful \\
\hline & & & $\mathrm{T} 8$ & .64 & .428 & attitudinal content appropr. \\
\hline & & & T14 & .62 & .406 & assessmt strategies appropr. \\
\hline & & & T5 & .62 & .420 & tchg content appropriate \\
\hline & & & $\mathrm{T} 6$ & .61 & .373 & facts/concepts appropriate \\
\hline & & & $\mathrm{T} 3$ & .56 & .435 & teaching objectives clear \\
\hline & & & $\mathrm{T} 2$ & .51 & .394 & tchr explained rationale \\
\hline & & & T9 & .49 & .325 & tchr encouraged stu. involvmt \\
\hline & & & $\mathrm{T} 4$ & .48 & .485 & tchg objectives helpful \\
\hline & & & $\mathrm{T} 12$ & .44 & .393 & time distribution appropriate \\
\hline & & & $\mathrm{T} 11$ & .43 & .224 & materials appropriate \\
\hline \multirow{15}{*}{$\begin{array}{l}\text { D2. Learning } \\
\text { process }\end{array}$} & \multirow[t]{15}{*}{39.815} & \multirow[t]{15}{*}{16.851} & L25 & .75 & .570 & planned \& regulated my lrng \\
\hline & & & $\mathrm{L} 30$ & .71 & .538 & my lrng process appropriate \\
\hline & & & L21 & .71 & .544 & facts/concepts covered well \\
\hline & & & L27 & .63 & .409 & spent time adequately \\
\hline & & & L24 & .54 & .384 & actively involved in lrng \\
\hline & & & L19 & .53 & .406 & my lrng objectives helpful \\
\hline & & & L22 & .52 & .405 & procedures practiced \\
\hline & & & L20 & .49 & .332 & learning content appropriated \\
\hline & & & L29 & .47 & .229 & self-evaluation of learning \\
\hline & & & L16 & .45 & .409 & general structure understood \\
\hline & & & L18 & .44 & .409 & clear learning objectives \\
\hline & & & L17 & .44 & .383 & importance of lrng was clear \\
\hline & & & L28 & .42 & .381 & regular attendance \\
\hline & & & L23 & .40 & .301 & attitudinal content acquired \\
\hline & & & L26 & .40 & .300 & materials sufficient \\
\hline
\end{tabular}

Confirmatory factor analysis was performed on the model using AMOS (op. cit.). The results from CFA were considered in the light of the absolute-fit statistics: CFI, TLI, RMSEA 
and Chi-Squared. To interpret the output statistics, CFI and TLI values close to .90 indicate a good fit; RMSEA values in the 0.05-0.08 range represent reasonable approximation errors in the population (Byrne, 2001). These indices are not exactly a good example of SEM's best fit, but it has been demonstrated recently that the choice of cutoff values depends on model specifications, degrees of freedom, and sample size (Chen , Curran, Bollen, Kirby, \& Paxton, 2008). Therefore, in global terms, the model can be considered defensible and valid, if we appeal to the fact that our sample size is relatively small. Table 5 summarizes these statistics for the default models. Figures 1 and 2 show the graphic outputs from AMOS.
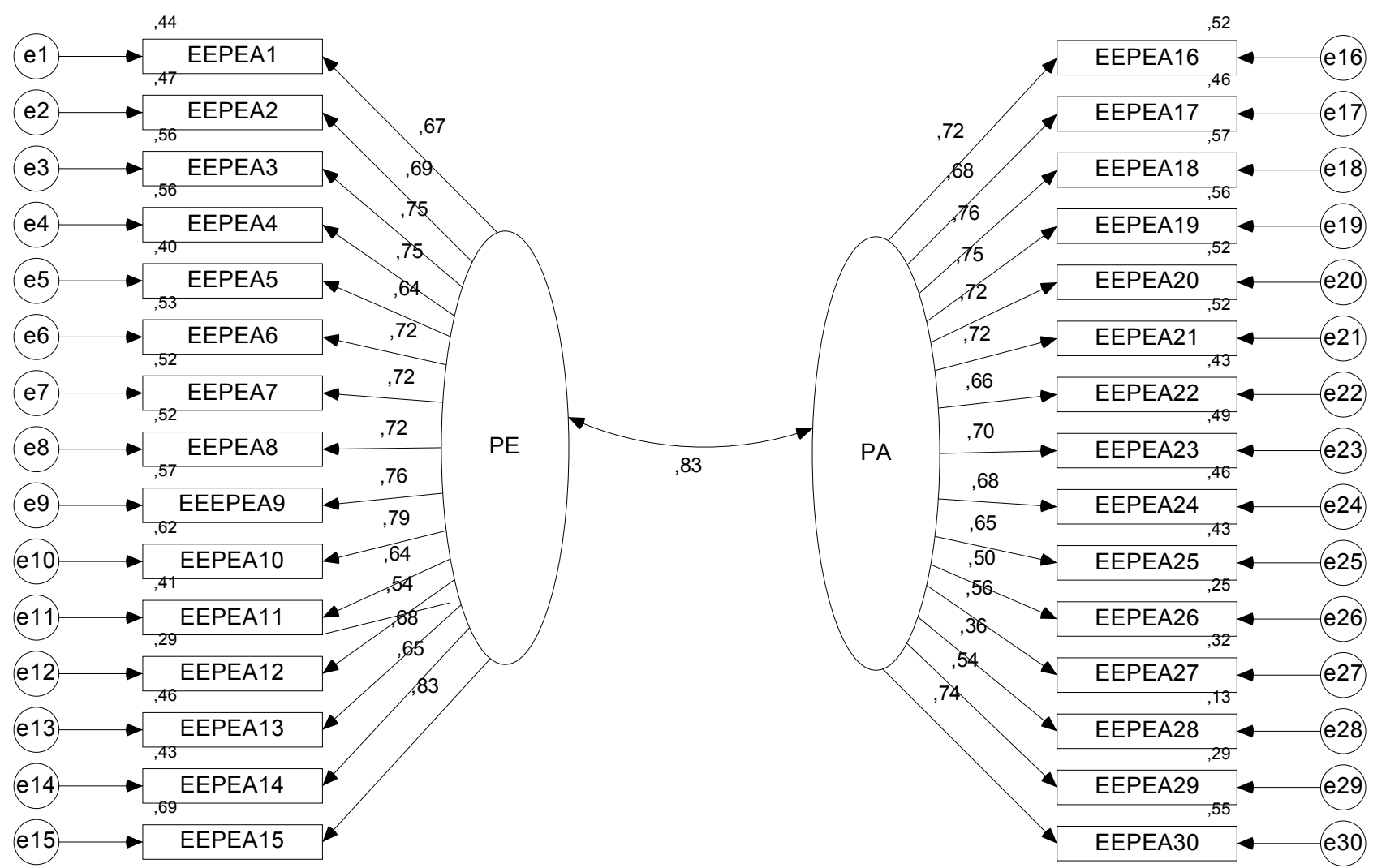

Figure 1. R\&D Project (2005-2008). Spain $(\mathrm{n}=1250)$ 

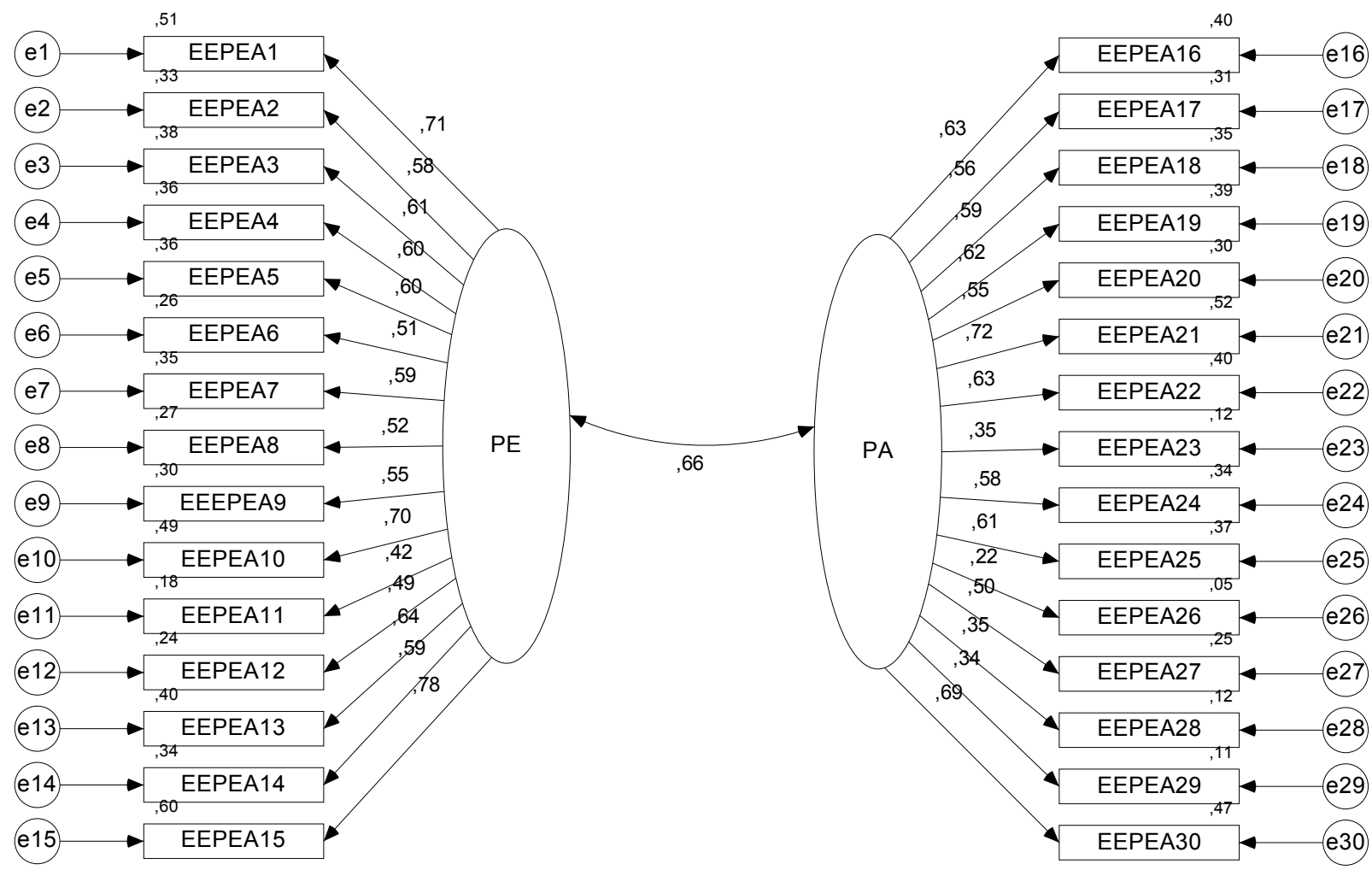

Figure 2. R\&D Project (2004-2005). UK (n=275)

Table 5. Results for Confirmatory Factor Analysis in two-factor model

\begin{tabular}{lcccccccc}
\hline \multicolumn{1}{c}{ Model } & $\mathrm{N}$ & $C F I$ & GFI & TLI & RMSEA & Chi.Squared & Degree of F. & Probability \\
\hline 1. Spain & 1250 & .901 & .912 & .913 & .056 & 5065.800 & 404 & .000 \\
2. UK & 208 & .868 & .885 & .841 & .050 & 776.296 & 404 & .000 \\
\hline
\end{tabular}

\section{External Validity Criteria}

Correlation of the Perception of the Teaching-Learning Process (ATLP-S) with Learning Approach (R-SRQ-2F) and Experiences of Teaching-Learning (ETLQ)

The first means for establishing the external validity of the ATLP-S Scale was to perform bivariate Pearson correlations with the other scales. For learning approaches (R-SRQ$2 F$ ), significant positive correlations appear for perception of the overall TL process with both the teaching and learning processes, and also for the deep learning approach with its components. This is true for both samples, although greater significance was seen in the British 
sample. Conversely, significant negative correlations appear between the surface approach and the perception of processes. Correlations are intense but low, meaning a strongly significant relationship that guarantees the independence of the related variables.

The intense correlations and modulation by the students' country of origin deserve special mention. In the British students, a strong positive association appeared between the deep approach and perception of the TL process, and a negative association appeared between the surface approach and perception of the TL process (Table 6). In Spanish students, however, the negative relationship was consistent with the above result, but with less intensity of the association.

As for correlation with teaching-learning experiences (ETLQ), results show a markedly significant relationship between each of the processes and the different elements of this questionnaire. Thus, total perception of the TL process is significantly correlated with the Total on the Experiences of Teaching and Learning Questionnaire, as well as with its different dimensions. The different cultural value given to the factor "level of demands" is worthy of note. In the Spanish sample, level of demands has a significant, negative correlation with satisfaction with the TL process, while in the British sample, the correlation is positive. Both results are shown in Table 6.

Degree of Interdependence between Perception of the Teaching-Learning Process (ATLP-S) and Learning Approach (R-SPQ-2F) and Experiences of Teaching-Learning (TLQ)

A second way to establish an external validity criterion for the ATLP-S Scale is to determine the relationship between the assessed construct and another preset one. In order to do so, cluster analyses were carried out for determining the low-medium-high subjects in terms of their satisfaction with the teaching-learning process. Results show a consistent effect and significant differences in interdependence levels. The level of perception or satisfaction with the teaching and learning process (low-medium-high) reveals significant differences in learning approach (deep or surface) in both samples. Thus, the best perception of the teaching and learning process involves a deep approach over a surface approach. The opposite effect also occurs. 
Table 6. Correlations of the Scale for the Assessment of the Teaching Learning Process $(A T L P-S)$ with Learning Approach $(R-S P Q-2 F)$ and Experiences of Teaching and Learning (ETL)

\begin{tabular}{|c|c|c|c|c|c|c|}
\hline Spain & Deep & $\mathrm{DM}$ & DS & Surface & SM & $\mathrm{SS} \quad(\mathrm{n}=930)$ \\
\hline $\mathrm{TP}$ & $.095 *$ & $.123 * * *$ & .054 & $-.171 * * *$ & $-.131 * *$ & $-.176 * * *$ \\
\hline LP & $.273 * * *$ & $.265 * * *$ & $.240 * * *$ & $-.188 * * *$ & $-.142 * *$ & $-.197 * * *$ \\
\hline TLP & $.191 * * *$ & $.204 * * *$ & $.151 * * *$ & $-.194 * * *$ & $.148 * * *$ & $-.202 * * *$ \\
\hline$U K$ & Deep & DM & DS & Surface & SM & SS $\quad(n=208)$ \\
\hline $\mathrm{TP}$ & $.341 * * *$ & $.325^{* *}$ & $.314 * *$ & $.500 * * *$ & $-.483 * * *$ & $-.439 * * *$ \\
\hline LP & $.483 * * *$ & $.452 * * *$ & $.451 * * *$ &.$-372 * *$ & $-.425 * *$ & $-.264 * * *$ \\
\hline TLP & $.468 * * *$ & $.438 * * *$ & $.436 * * *$ &.$-499 * * *$ & $-.512 * * *$ & $-.407 * * *$ \\
\hline Spain & ETL.T & ETL.L & ETL.DEM & ETL.CONT & ETL.TOTAL & $(\mathrm{n}=930)$ \\
\hline $\mathrm{TP}$ & $.692 * * *$ & $.630 * * *$ & $-.258 * * *$ & $.401 * * *$ & $.604 * * *$ & \\
\hline LP & $.174 * * *$ & $.406 * * *$ & $-.216 * * *$ & $.426 * * *$ & $.624 * * *$ & \\
\hline TLP & $.304 * * *$ & $.722 * * *$ & $-.260 * * *$ & $.448 * * *$ & $.666 * * *$ & \\
\hline$U K$ & ETL.T & ETL.L & ETL.DEM & ETL.CONT & ETL.TOTAL & $(n=208)$ \\
\hline TP & $.691 * * *$ & $.373 * * *$ & $.205 * * *$ & $.614 * * *$ & $.673 * * *$ & \\
\hline LP & $.449 * * *$ & $.455 * * *$ & $.334 * * *$ & $.537 * * *$ & $.545 * * *$ & \\
\hline TLP & $.469 * * *$ & $.647 * * *$ & $.300 * * *$ & $.650 * * *$ & $.688 * * *$ & \\
\hline
\end{tabular}

$* * \mathrm{p}<.01 * * * \mathrm{p}<.001$

$T P=$ Teaching Process; $L P=$ Learning Process; $T L P=$ Teaching-Learning Process

$\mathrm{DM}=$ Deep Motivation; DS= Deep Strategy; SM= Surface Motivation; SS= Surface Strategy

ETLL= Learning Experience; ETLT= Teaching Experience; ETL.DEM= Experience of Demands, ETL.CONT= Experience of Content, ETLTOTAL= Total Experience.

More specifically, in both samples, students with a high perception of the teaching process show significant differences with respect to students with a low perception, scoring higher on deep approach and lower on surface approach. This effect persists in the specific analysis of motivation and deep strategy, and is even more consistent in the case of motivation and surface strategy. As for perception of the learning process, the statistical effect is more powerful, showing the same trend and with greater strength, indicating that a high perception of the learning process involves significantly greater levels of deep approach and lower levels of surface approach. This trend is also appreciable in motivation and in strategy, indicating greater levels of satisfaction with the learning process where students have greater levels of motivation and deep strategy. See Table 7. 
Table 7. Interdependence relations analysis with levels of the Assessment of the Teaching Learning Process (ATLP-S) and Learning Approach (R-SPQ-2F)

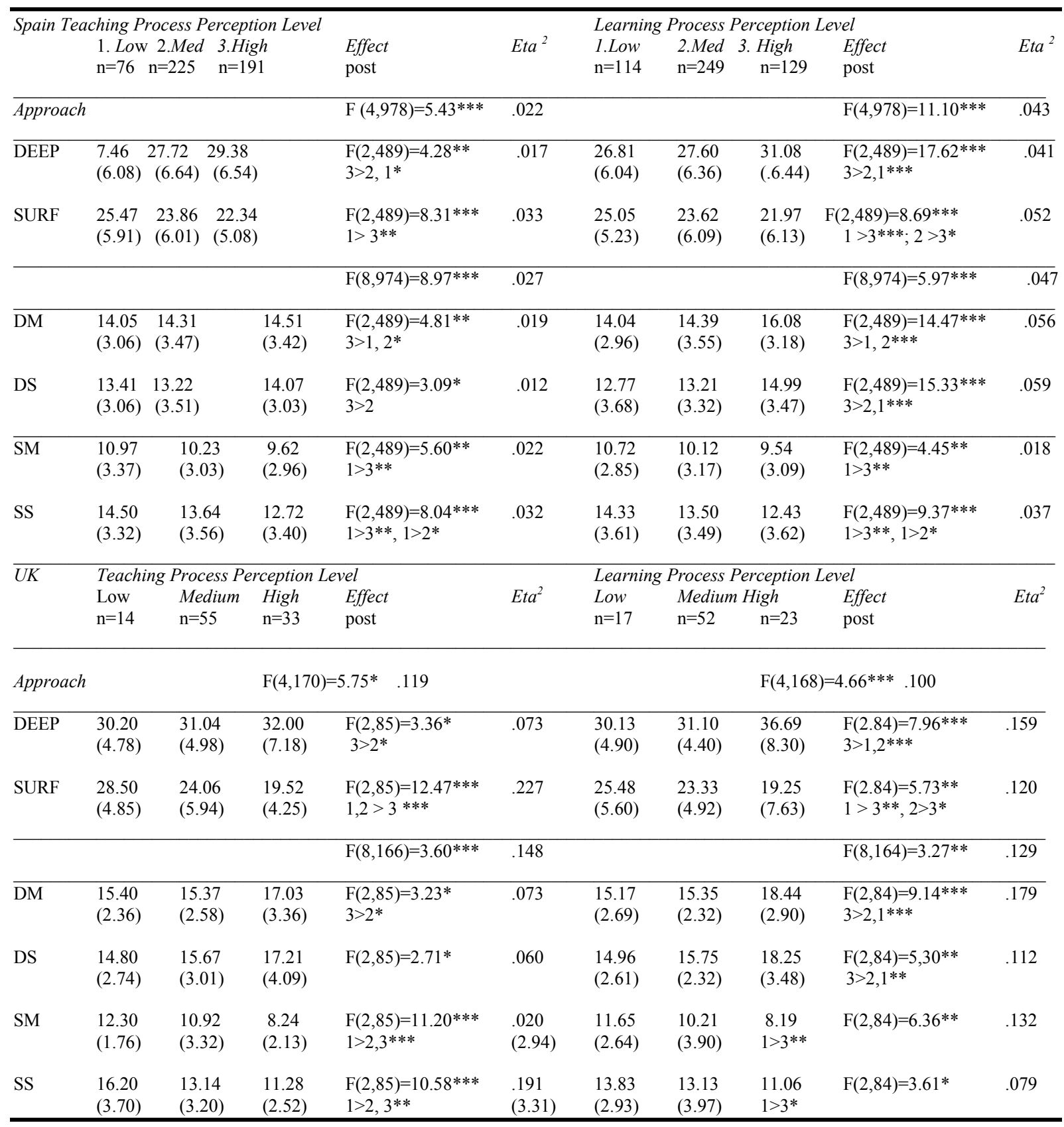

$* \mathrm{p}<.05, * * \mathrm{p}<.01, * * * \mathrm{p}<.001$

DM= Deep Motivation; DS= Deep Strategy; SM= Surface Motivation; SS= Surface Strategy

In complementary fashion, high-medium-low levels of perception of the teaching and learning process are accompanied by similar levels of the experience of teaching-learning, in total experience, experience of teaching, experience of learning, and of learning content, in the samples of Spanish and British students. One noteworthy effect that differentiates between students is the "experience of demands" variable (ETLDE). Mean scores on this variable for Spanish students are greater than for the British, both for the teaching process and the learning 
process. Moreover, Spanish students who have a low perception of the teaching and learning process report greater levels of demanding experiences than do those with a high perception of the process. However, the opposite occurs in the case of British students, where the students most satisfied with the teaching and learning process are those who report greater demands and requirements. See Table 8.

Table 8. Interdependence relations analysis with levels of the Assessment of the TeachingLearning Process (ATLP-S) and Experiences of Teaching and Learning (ETLQ).

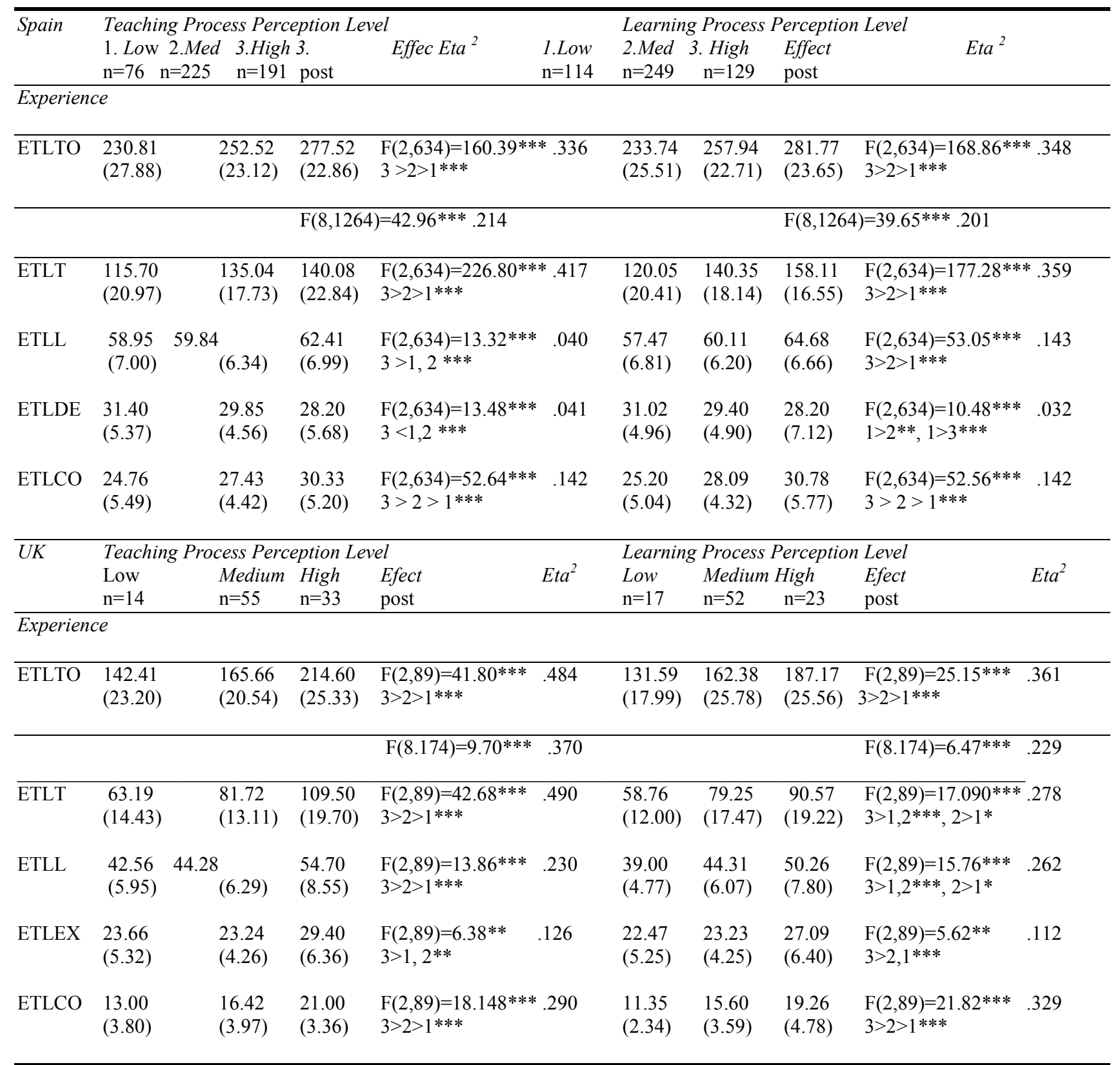




\section{Discussion and Conclusions}

We can make certain reflections about the aims of this study, based on results obtained. As for verification and assessment of the structural and relational aspects of this Scale, the results are encouraging. Statistical values relating to the instrument's soundness and validity are acceptable. As for the construct validity of the instrument, we have demonstrated that the two-factor structure is consistent for the construct "Teaching Learning Process" as postulated in the theoretical basis for this instrument, defined by several authors (Entwistle \& Tait, op cit). Another relevant result refers to the higher factorial weight of the learning process in the first order factorial structure. In order to better understand this result, we must consider the fact that students pay more attention to assessment of the teaching process than to assessing the learning process.

Regarding the instrument's external validity, the results are also consistent, since there are different interdependent relationships among the perception of variables which exist in an academic environment. Variations in scores for the learning process have proved that the Scale is sensitive to the latter's influence on the teaching-learning process. We have also demonstrated that assessment of the teaching process and of the learning process are interdependent, whether we speak of students' approach to learning, their perception of teaching and learning experiences, or academic performance. These results provide empirical evidence of the scale's external validity.

The nature of one's learning approach, whether surface or deep, is determined once again by affective (motivational) and cognitive (strategic) components (Biggs et al.., 2001). Some empirical studies have demonstrated a high positive correlation between the motivational and strategic components and a given approach, and a null or negative correlation with the opposite approach (Berbén, 2005; Biggs et al.., 2001; Harris, Wickline, \& Iliescu, 2004; Leung \& Chan, 2001; Pilcher, 2002). Other prior studies have shown similar relationships between learning approaches and self-regulation (Phan, 2008) and between the teachinglearning process and self-regulation (De la Fuente, Justicia, \& Berben, 2005). Phan (2008) performed a regression analysis and concluded that deep motivation predicted self-regulated learning in 603 university students in the South Pacific. Similarly, De la Fuente et al. (2005) showed that self-regulation has a positive correlation with the deep approach and a negative 
correlation with the surface approach in 492 university students in Almería and Granada (Spain). Furthermore, the cluster analysis results revealed one group of students $(n=99)$ with more surface learning and lacking in self-regulation, and another group $(n=127)$ which learns more deeply and is more self-regulated. However, the current investigation has established a consistent relationship between perception of the teaching-learning process, learning approach, and teaching-learning experiences, which to date had not been established with sufficient precision.

In summary, this instrument can contribute to improving the teaching-learning process at a university level. On one hand, it helps students change some wrong conceptions about learning and teaching (Eklund-Myrskog, 1998; Kember, Jenkins, \& Chi, 2004; Scouller, 1998), since it allows student participation in assessment of the teaching and learning processes under way (Coll et al., 2007; Husbands \& Fosh, 1993; Kelvin, 1993; Kember \& Wong, 2000; Wehmeyer, et al., 2003, 2007). On the other hand, evaluation of the quality of the teaching-learning process at university is made possible (De la Fuente \& Cardelle-Elawar, 2009; Enmanuel \& Adams, 2006; Ginns, Prosser, \& Barri, 2007; Harvey \& Green, 1993; Print \& Hattie, 1997; Zohar \& Bracha, 2008). It also gives teaching staff the opportunity to reflect on these processes (De la Fuente, Justicia, \& Berben, 2005; Entwistle \& Peterson, 2004; Jarvinen \& Kohonen, 1995; Pratt, 1997), especially when teachers are new graduates with a great deal of formative requirements (Trigwell, Prosser \& Taylor, 1994).

Nonetheless, the current research has limitations which should be addressed. The reduced size of the British sample is a significant obstacle in carrying out the analyses. It will be necessary to replicate this work with broader British samples. Future lines of research are suggested, such as performing cultural validation studies, studying relationships with teaching and learning approaches, and above all, studying the Aptitude-Treatment Interaction (ATI), in order to consider how different approaches to learning and teaching interact in university students. 


\section{Acknowledgement}

This work was carried out under the auspices of:

1) RD\&I Project ref. BSO2003-06493. Improving self-regulated learning in university students through online regulatory strategies for teaching. Ministry of Science and Technology and European Found Social (2003-2006), Spain.

2) RD\&I Project ref. SEJ2007-66843/educ. The assessment of improvement in the teachinglearning process and of competencies, in the European Space for Higher Education: Model and Protocols. Ministry of Education and Science European Found Social (2007-2010). Spain 


\section{References}

Arbuckle, J.L., (2008). AMOS 16.0. Chicago: SPSS Corporation.

Apodaca, P. \& Grad, H. (2005). The dimensionality of student ratings of teaching: integration of uni- and multidimensional models. Studies in Higher Education, 30(6), 723-748.

Berbén, A.B.G. (2005). A study of approaches to learning in students of Educational and School Psychology. Electronic Journal of Research in Educational Psychology, 6, 3(2), 109-126.

Bentler, P. M. (1995). EQS Structural equations program manual. Encino, CA: Multivariate Software Inc.

Bentler, P. M., \& Dijkstra, T. (2000). Efficient estimation via linearization in structural models. In P. R. Krishnaiah (Ed.), Multivariate Analysis VI (9-42). Amsterdam: NorthHolland

Bigg, J. (2001). Teaching for Quality Learning at University ( $3^{\text {rd }}$ ed.). Buckingham: Open University Press.

Biggs, J., Kember, D. \& Leung, D. (2001). The revised two-factor Study Process Questionnaire: R-SPQ-2F. British Journal of Educational Psychology, 71, 133-149.

Butler, R. \& Shibaz, L. (2009). Achievement goals for teaching as predictor of students' perception of instructional practices and students' help seeking and cheating. Learning \& Instruction, 18(59), 453-467.

Byrne, B. (2001). Structural Equation Modelling in AMOS; Basic Concepts, Applications, and Programming. New Jersey: Lawrence Erlbaum.

Cardelle-Elawar, M.C., Irving, L., \& Sanz de Acedo, M.L. (2007). A cross cultural analysis of Motivational Factors that Influence the Professional Identity. Electronic Journal of Research in Educational Psychology, 5(3), 565-592.

Coll, C., Rochera, M.J., Mayordomo, R.M., \& Naranjo, M. (2007). Continuous assessment and support for learning. An experience in educational innovation with ICT support in higher education. Electronic Journal of Research in Educational Psychology, 5(3), 783 804.

Chen, F., Curran, P.J., Bollen, K.A., Kirby, J., \& Paxton, P. (2008). An empirical evaluation of the use of fixed cutoff points in RMSEA Test Statistic in Structural Equation Models. Sociological Methods \& Research, 36(4), 462-494. 
De la Fuente, J. \& Cardelle-Elawar, M.C. (2009). Research on action-emotion style and study habits: Effects of individual differences on learning and academic performance of undergraduate students. Learning \& Individual Differences, 19 (5), 567-576.

De la Fuente, J. \& Eissa, M.A. (2010). International Handbook on Applying Self-Regulated Learning in Different Settings. Almería (Spain): Education \& Psychology I+D+i, ePublishing Series.

De la Fuente, J. \& Justicia, F. (2001). Escala para la Evaluación del Proceso de EnseñanzaAprendizaje, EEPEA. [Scale for the Assessment of the Teaching-Learning Process, ATLP.] Almería (spain): University Publications Service.

De la Fuente, J. \& Justicia, F. (2007). The DEDEPRO Model for Regulating Teaching and Learning: recent advances. Electronic Journal of Research in Educational Psychology, $5(3), 535-564$.

De la Fuente, J. \& Justicia, F. (2010). Assessment of the Teaching-Learning Process (ATLP). Almería (Spain): Education \& Psychology I+D+i, e-Publishing Series. In press.

De la Fuente, J., Justicia, F. \& Berbén, A.B.G. (2005). Enfoques de aprendizaje, percepción del proceso de enseñanza/aprendizaje y rendimiento de universitarios. [Learning approaches, perception of the teaching/learning process and performance of university students.] Revista de Psicología y Educación, 1(2), 87-102.

De la Fuente, J., Justicia, F., \& Berbén, A.B.G. (2006). An Interactive Model of Regulated Teaching and Self-regulated Learning. International Journal of Learning, 12(7), 217-225. De la Fuente, J. \& Martínez, J. M. (2007). Scale for Interactive Assessment of the TeachingLearning Process, IATLP. Almería (Spain): Education \& Psychology $\mathrm{I}+\mathrm{D}+\mathrm{i}$, e-Publishing Series.

Eklund-Myrskog, G. (1998). Students' conceptions of learning in different educational contexts. Higher Education, 35, 299-316.

Emanuel, R. \& Adams, J. N. (2006). Assessing college student perceptions of instructor customer service via the quality of instructor service to students (QISS) questionnaire. Assessment and Evaluation in Higher Education, 31(5), 535-549.

Entwistle, N., \& McCune, V. (2004). The conceptual basis of study strategy inventories. Educational Psychology Review, 16, 325-345.

Entwistle, N.J. \& Peterson, E.R. (2004). Conceptions of learning and knowledge in higher education: relationships with study behavior and influences of learning environments. International Journal of Educational Research, 41(3), 407-428. 
Entwistle, N. \& Tait, H. (1990). Approaches to learning, evaluations of teaching, and preferences for contrasting academic environments. Higher Education, 19, 169-194.

Ginns, P., Prosser, M., \& Barrie, S. (2007). Students' perceptions of teaching quality in higher education: the perspective of currently enrolled students. Studies in Higher Education, $32(5), 603-615$.

Harris, J.M., Wickline, V.B., \& Iliescu, C.S. (2004). Construct Validation of Revised Study Process Questionnaire (R-SPQ-2F) with an American College Sample. Poster presented at the 16th Annual Convention, May, Chicago (Illinois). Accessed on June 10, 2004 at: http://www.psychologicalscience.org/convention/program/search/results.cfm? Author $=40$ 18

Harvey, L. \& Green, D. (1993). Defining Quality. Assessment \& Evaluation in Higher Education, $18(1), 9-34$.

Hounsell, D., Entwistle, N., et al. (2001-2003). ETL project. Enhancing Teaching-Leaning Environments in Undergraduate Courses. The School of Education, University of Edinburgh.

Hugener, I., Pauli, C., Reusser, K., Lipowsky, F., Rakoczy, K., \& Klieme, E. (2009). Teaching patterns and learning quality of Swiss and German mathematics lesson. Learning \& Instruction, 19(1), 66-78.

Husbands, C. T \& Fosh, P. (1993). Students' evaluation of Teaching in Higher Education: experiences from European countries and some implications for practice (1). Assessment \& Evaluation in Higher Education, 18(2), 95-114.

Jarvinen, A. \& Kohonen, V. (1995). Promoting Professional Development in Higher Education through Portfolio Assessment. Assessment \& Evaluation in Higher Education, 20(1), 25-36.

Justicia, F., Pichardo, M. C. Cano, C., Berbén, A.B.G. \& De la Fuente, J. (2008). The revised Two-Factor Study Process Questionnaire (R-SPQ-2F): Exploratory and Confirmatory Factor Analyses at Item Level. European Journal of Psychology of Education, 23(3), 355-372.

Kelvin, A. (1993). Increasing students' participation in the learning process. Higher Education, 26, 449-469.

Kember, D. \& Wong, A. (2000). Implications for evaluation from a study of students' perceptions of good and poor teaching. Higher Education, 40(1), 69-97.

Kember, D., Jenkins, W. \& Chi, K. (2004). Adult students' perceptions of good teaching as a 
function of their conceptions of learning-Part 2. Implications for the evaluation of teaching. Studies in Continuing Education, 26(1), 81-97.

Kinchin, I.M., Lygo-Baker, S., \& Hay, D.B. (2008). Universities as centres of non-learning. Studies in Higher Education, 33(1), 89-103.

Klassen, R.M. (2004). Optimism and realism: a review of self-efficacy from a cross-cultural perspective. International Journal of Psychology, 39(3), 205-230.

Leung, M. \& Chan, K. (2001).Construct Validity and Psychometric Properties of the Revised Two-factor Study Process Questionnaire (R-SPQ-2F) in the Hong Kong Context. Paper presented at the AARE 2001 Conference, December, Perth (Australia).

Oyserman, D., Coon H., \& Kemmelmeier, M. (2002). Rethinking Individualism and Collectivism: Evaluation of Theoretical Assumptions and Meta-Analyses. Psychological Bulletin, 128(1), 3-72.

Phan, H.P. (2008). Multiple regression analysis of epistemological beliefs, learning approaches, and self-regulated learning. Electronic Journal Research in Education Psychology, 14, 6(1), 157-184.

Pilcher, R. (2002). Analysis of the Approaches to Learning by Accounting and Business Students in Australia- Evaluating the Classroom. Poster presented at the 2003 Annual Meeting of the American Accounting Association, August, Honolulu, (Hawaii). Accessed on October 8th, 2003, at: http://aaahq.org/AM2003/ StrategicLearning01/05.htm

Postareff, L. \& Lindblom-Ylänne, S. (2008). Variation in teachers' description of teaching: broadening the understanding of teaching higher education. Learning and Instruction, $18(2), 109-120$.

Pratt, D.D. (1997). Reconceptualizing the evaluation of teaching in higher education. Higher Education, 34, 23-44.

Print, M. \& Hattie, J. (1997). Measuring quality in universities: An approach to weighting research productivity. Higher Education, 33, 453-469.

Ramsden, P. (2003). Learning to teach in higher education (2nd. Ed.) New York: Roudlege Falmer.

Scouller, K. (1998). The influence of assessment method on students' learning approaches: Multiple choice question examination versus assignment essay. Higher Education, 35, 453-472. 
Trigwell, K. \& Prosser, M. (2004). Development and use of The Approach to Teaching Inventory. Educational Psychology Review, 16, 409-424.

Trigwell, K., Prosser, M. \& Taylor, P. (1994). Qualitative differences in approaches to teaching first year university science. Higher Education, 27, 75-84.

Tweed, R.G. \& Lehman, D.R. (2002). Learning considered within a cultural context. American Psychologist, 57(2), 89-99.

Vermunt, J.D. \& Verloop, N. (1999). Congruence and friction between learning and teaching. Learning and Instruction, 9, 257-280.

Weinstein, C.D. \& Mayer, R.E. (1986). The teaching of learning strategies. In M.Wittrock, Handbook of Research of Teaching (pp. 257-274). New York: MacMillan.

Wehmeyer, M.L., Abery, B., Mithaug, D.E., \& Stancliffe, R.J. (2003). Theory in SelfDetermination: Foundations for Educational Practice. Springfield, IL: Charles C Thomas Publisher, LTD.

Wehmeyer, M.L., Agran, M., Hughes, C., Martin, J.E., Mithaug, D.E., \& Palmer, S.B. (2007). Promoting self-determination in students with intellectual and developmental disabilities. New York: Guilford Press.

Zohar, A. \& Bracha, P. (2008). The effects of explicit teaching of metastrategic knowledge on low- and high-achieving students. Learning \& Instruction, 18(2), 337-352. 
Appendix I. Items that make up the ATLP-S (De la Fuente \& Justicia, 2001, 2010).

T1. The general approach is useful in my educational development.

T2. The teacher explained the rationale for what we were learning.

T3. Teaching objectives were clear.

T4. The teaching objectives helped me in building my own knowledge.

T5. The teaching content was appropriate.

T6. Course content which addressed facts and concepts seemed appropriate to me.

T7. Course content which taught procedures seemed appropriate to me.

T8. Course content which addressed attitudes, values and rules seemed appropriate to me.

T9. The teacher encouraged my involvement in the learning process.

T10. The teaching approach encouraged relevant, useful learning.

T11. Materials used in the course / module were appropriate.

T12. The time dedicated to each topic was appropriate.

T13. The teacher's behavior (interaction, attitude, etc.) was appropriate.

T14. I think the assessment strategies used were appropriate.

T15. In general, the teaching process was appropriate.

L16. I understood the general structure of the course / module.

L17. The importance of what we were learning was clear to me.

L18. I had clear learning objectives.

L19. My learning objectives helped me build my own knowledge.

L20. I was able to sort out the content to be learned.

L21. I have adequately worked through the facts and concepts to be learned in this course / module.

L22. I have put into practice the procedures to be learned in this course / module

L23. I have acquired the attitudes, values and rules to be learned in this course / module.

L24. I was actively involved in the learning process.

L25. I adequately planned and regulated my own learning.

L26. The resource materials I used (reference books, etc.) were sufficient.

L27. The time I dedicated to learning each topic was adequate.

L28. I had regular attendance, that is, I attended most classes.

L29. I used appropriate self-evaluation strategies during the learning process.

L30. In general, my learning process was appropriate. 